\title{
Engineering Students' Participations and Creativity Towards Flipped Classroom Method: A Case Study
}

\author{
Siti Khoiruli Ummah \\ \{ khoiruliummah@umm.ac.id \} \\ University of Muhammadiyah Malang, Jalan Raya Tlogomas 246 Malang
}

\begin{abstract}
Blended Learning using Canvas became a familiar method in 2019 because of the easiest access and the centralized system management in university. This paper described the findings of the case study focusing on the engineering students' participation and the creativity in the implementation of flipped classroom method emphasizing group discussion and students' answer sheets. The findings were optimally reached from online group discussion, paper-based test, and online test using a qualitative approach. The findings were surprised because the engineering students through the flipped classroom were more active than in the classroom. There were more comment in group discussion and the answer from discussions' topic were vary. The discussion was more interactive because every student have different questions that must be answered by other students. The engineering graduated students could answer fluently and vary. The students' answer on the paper-based test and online test were varied and all the questions were answered correctly. It could be said that flipped classroom optimally implemented so that change the students' participation and creativity significantly.
\end{abstract}

Keywords: Blended learning, Canvas, creativity, engineering students, flipped classroom, online group discussion, students' participations

\section{Introduction}

Learning environment could be integrated using technology in the form of e-learning. The development of e-learning seen on the implementation of the Learning Management System (LMS) has become the main part of the learning process, specifically in university. LMS is an application to be used in online learning. Online learning could be combined with face-to-face learning. This learning usually called blended learning. Blended learning uses the technology as the media that connect lecturer, instructional media, and students. Technology usually used in outside of the class [1]. Students used the internet to find the reference or the solution of the problem that has been delivered by a lecturer in the class.

The University of Muhammadiyah Malang in Indonesia (usually known as UMM) that was the site for this study, have a department, who has known in society that is Informatics Engineering. The informatics engineering class was dominated by male students. Mathematics is one of the courses that was learned by students. They learn about applied mathematics such as discrete mathematics, topology, graph theory, combinatorics, and calculus. Based on the observation, the learning model that usually implemented is the traditional classroom (usually called by teacher-centered learning). It could be seen that the traditional classroom was dominated by the teacher. Lecturer usually takes procedural-type problems that has been 
presented on the textbook and student capture or copy the solution of problems that were written on board. This case in line with the previous study that said professor usually foster active learning in traditional classroom [2]. The engineering class usually proceed by lecturer explanation, solving the procedural problem in the team, and student writes their answer on board. Teacher discuss the answer on board and student capture using their phone or write the correct answer. Based on the observation, this learning makes the students feel bored and couldn't share their opinion about the solution to the problem. These activities make students must master all of the topics that was presented by the lecturer and needs an amount of time. The lecturer must ensure that student master a part of topics before moving the other topic [3].

One of the online learning media usually used in engineering class is Edmodo. Lecturer used Edmodo to deliver problem in the form of the pdf file. Students upload the solutions' problem and then the lecturer scores manually. In contrast, Edmodo could score and give feedback to students' answer sheet. It also provides the discussion forum but doesn't use by lecturer effectively. It can be said that Edmodo is a media to submit students' answer sheet. The traditional class still dominated in learning. Accordingly, there is an important need to change the learning environment, specifically, in engineering class.

The main purpose of this case study was to describe the implementation of the flipped classroom model in engineering class would affect the students' participation and creativity. The case study also investigate the difference between students' participation through online discussion and larger discussion in class. The creativity in answering problem described using indicators of fluency, flexibility, and originality. The use of LMS become new alternatives in learning because it also became a new policy in UMM. LMS is media in which web-based learning is used to deliver content, discuss, and evaluate using quizzes.

\subsection{Significance of Study}

The technology becomes adequately used in the learning environment. The learning environment appropriates to The $21^{\text {st }}$ Century Learning in which focused on the integration technology in daily life. Technology becomes a necessity to create students' learning independently [4]. The use of the flipped classroom model makes the students can take part in the learning. In contrast, the use of LMS doesn't guarantee the students' creativity and students' participation arise confidently. Therefore, this paper aimed to investigate when and how students' participation and creativity arise using the flipped classroom. Specifically, this paper focused on undergraduate engineering class by analyzing students' answer sheet and questionnaire. This paper hope identifies students' participant and creativity toward the flipped classroom.

\section{Literature Review}

There was more math content received by students in the amount of time in the traditional classroom [3], class briefly consisted of teacher-centered learning, that is teacher dominated to talk and students mostly listen and only take a note [5],[6]. The teacher usually writes the definitions and explain the solution of the problem step by step [7]. The lack of this method could be said that the students' habit to solve the problems using teachers' steps as the exercise. 


\subsection{Blended Learning}

There was so many solutions that offers math learning, one of them usually called The Blended Learning. This learning was an alternative teaching method to combine or integrate both traditional classroom teaching that was implemented in the class and using technology such as e-learning [8],[9]. The learning performs teacher to present the topic for the first time. Students must establish the idea that they have got from the teacher. If the students could establish the idea then the online learning would proceed [10]. Using blended learning, students could increase their interest and motivation. The students' elaboration could be one of the benefits of implementing blended learning. There is no limit for students to explore knowledge and create the students' life-long learning [11]. It is not only the students who get the benefits of blended learning but also the institution. The institution who implement blended learning could be said that they had been improved their learning environment. They had been improved lecturer being closed with technology and could promote their learning environment to the society.

\subsection{Flipped Classroom}

The implementation of blended learning varied. The blended learning models were differentiated into 7 models, station rotation, lab rotation, individual rotation, flipped classroom, flex, a la carte, and enriched virtual [12]. The flipped classroom had chosen to be implemented in engineering class because it could be more collaboratively during the learning process [12]. It could be helped engineering students who feel embarrassing to ask, answer or give opinions so that students could be more active in learning engagement [13][14]. The word 'flipping' generally means by course delivery that held in outside and inside of class. The outside class usually used to deliver content instruction while the inside class usually used to deliver the instructional content [13]. Some benefits of implementation flipped classroom are making students actively engaged in the smaller or larger discussion. [14][3].

The activity inside and outside class could be vary implemented [12]. The focus of the inside of class activity is answering the tasks through larger discussion. Students prepare questions about the instructional content that was presented online. The activity outside of class could be implemented through instructional content submission into e-learning or Learning Management System (LMS). Students could download, read and analyze the instructional content privately. The materials was so varied include worksheet for group discussion or larger discussion, modules, worksheet, and quizzes. These materials were designed to be learned individually. All the problem that presented in LMS solved in the class through larger discussion. The larger discussion would accommodate the students who prepared the question about the problem solution and students who didn't brave to ask in the classroom. It could be said that The Blended Learning combined the benefits of face-to-face learning and online learning. The differentiation of activity in inside and outside class using the flipped classroom could be seen in Table 1. 
Table 1. The Differentiation of inside and outside class using flipped classroom

\begin{tabular}{|c|c|c|}
\hline Activities & Inside Classroom & Outside Classroom \\
\hline Teaching Materials & $\begin{array}{l}\text { Explanation, } \\
\text { Demonstration verbally }\end{array}$ & $\begin{array}{l}\text { Online Module, Explanation } \\
\text { using Video }\end{array}$ \\
\hline Learning Activities & $\begin{array}{l}\text { Discuss the solution of the } \\
\text { problem that was } \\
\text { presented in LMS }\end{array}$ & $\begin{array}{l}\text { Discuss a problem discussion } \\
\text { that submitted into LMS }\end{array}$ \\
\hline $\begin{array}{l}\text { Formative } \\
\text { Assessment }\end{array}$ & Paper-based test & Online quizzes \\
\hline Homework & Read content online & Post-test \\
\hline Learning Objective & $\begin{array}{l}\text { Creating, Evaluating, } \\
\text { Analyzing }\end{array}$ & $\begin{array}{l}\text { Applying, Understanding, } \\
\text { Remembering }\end{array}$ \\
\hline
\end{tabular}

Table 1 resumed the difference activities inside the classroom and outside classroom based on the aspects of how teaching materials delivered by, learning activities, formative assessment, homework, and learning objective. The online learning in the outside classroom was more paperless and students must have computational skills. The important things in Table 1 could be seen by learning objective that would be reached. The online learning assumed that students take the preliminary study then learn materials using the activities remembering, understanding, and applying [12]. They could open their textbook or browse using the internet to solve the problem discussion. On the other hand, the online learning activities make students creating, evaluating, and analyzing because lecturer together with students discuss the complex problem to solve [12]. Lecturer asks and answer directly in the classroom. Using LMS, the lecturer could report students' activity progress through discussion. Lecturer scores the assignment and then export the file into a .xls file format.

\subsection{Learning Management System (LMS)}

LMS has a lot of platforms. One of them is Canvas. Canvas is an LMS platform that has been written in the UMM policy. Canvas could be said as an online application where the institution could set the domain and make the access centered. The institution could set the course, course lecturer and students. When the students set their course, it would create the course in Canvas automatically. The lecturer could post modules, assignment, discussion forum, video conference and quizzes [15]. The benefits of using Canvas were all the activities that lecturer post would be centered and being recorded by the university. The lecturer could analyze student participation and performance through duration and how many they post a comment in the discussion forum [15]. LMS Canvas need low-budget because of its characterized as opensource LMS [16]. This LMS was capable to provide math equations, scientific symbols, graphics, and embed code. It represents all content in Math without converting into LaTEX form. LMS Canvas has several menus that are Home, Account, Dashboard, Courses, Calendar, and Inbox. While the dashboard was opened, the course that has been created displayed alphabetically.

\subsection{Students Participations}

The focus of the research, as mentioned earlier, to investigate students' participant. Using the questionnaire, students were asked how much their participation in the online discussion. 
The participation has indicators such as involving problem-solving activities, positive comment, negative comment, asking questions, and argumentation [17][18]. The positive comments come from the student answer about their friends' comments. Students could give the appreciation of friends' correct answer or advices for the next comment. Students possible give negative comments while they bullied the incorrect answer. Students' participation also was seen by how much they give a question for a lecturer or the other students. The argumentation usually comes while the student feels disagree for the other comment. Then, they argued using their thinking.

\subsection{Students Creativity}

The focus of the research, as mentioned earlier, also to investigate students' creativity. In mathematics, creativity related closely with problem-solving. Creativity was an ability to think about solving a problem in different ways [19]. Creative thinking could be called by divergent thinking, that is, contained elements, that is, fluency, flexibility, originality, and elaboration. The fluency means students generated several solutions for a problem. The flexibility means students could produce a different way or procedure to solve an open-ended problem. The originality was shown by students' answer was new and different with the other. The elaboration means students could create interpretation [20].

\subsection{Statement of Flipped Classroom Problem}

Capitalizing on the flipped classroom theory that has been presented before, the flipped classroom, specifically use LMS, has several problems for beginners [11]. The lack was more focused on participants choosing, learning style, engagement, and creativity [1], [3], [6], [12], [15], [21]. Overall, whereas studies have described the benefits of the implementation of the flipped classroom, specifically in motivation, perceptions, and performance, in which all of the ability was improved, frequently describing less creativity to solve problems indicated by the same answer among students. In contrast, the students' creativity less describes in previous studies. Focusing on students' participation and creativity, was important to investigate how the impact of the flipping classroom using LMS Canvas in engineering class.

\section{Study Design}

There were more math content received by students in amount of time in traditional classroom [3], class briefly consisted of teacher-centered learning, that is teacher dominated At the mid-semester of the last semester on the academic year 2018-2019, the Department of Mathematics Education was implemented blended learning that has been being the new university's policy. The university was mainly serving students from a different department. The participating course had 17 students with 10 males and 7 females. The lecturer was 30 years old and had been teaching for 5 years. The research was the mixed-method using qualitative and quantitative data to a pilot course and its new experiences of the blended learning approach using the flipped classroom method. The research questions how the flipped classroom method implemented using LMS Canvas in studying discrete mathematics for engineering students. Furthermore, this research wanted to describe, how were the flipped classroom support students' participation and creativity? 
The research data consisted of students' answering and teacher observations about the reached creativity indicators. After the course, the students answer the questionnaire using Google Form about their feeling about the implementation of the flipped classroom. The answer of post-test and questionnaire have been qualitatively analyzed to describe their learning participation, specifically in the larger discussion, and creatively solution of the openendedproblems.

The data collection was collected during the course and taken by observation, giving posttest, and giving questionnaire. The other lecturer, as an observer, observed the course while he was sitting at the back of the classroom and walking around to observe all of the teacher and students activities. The observer also took observational field notes during observations. This procedure was adapted from the previous study [5].

The flipped classroom method used repetition method in which students learn through inclass sessions followed by out-class sessions during five meetings. It scheduled two days per week for 100 minutes per session. The student could read the content a day before the class held. The qualitative data has been collected during the course through larger discussion using LMS Canvas and larger discussion in the classroom. The quantitative data has been collected through the answer to the questionnaire. The data have been analyzed by mixed-method theory. The major advantage that flipped classroom offers is improved opportunity for independent learning and students' confidently share their opinions. The schedule and distribution of material could be seen in Table 2.

Table 2. Schedule and Content Distribution

\begin{tabular}{cll}
\hline Meetings & \multicolumn{1}{c}{ Content } & \multicolumn{1}{c}{ Method } \\
1 & Introduction of Tree & Inside Classroom \\
2 & Properties of Tree & Outside Classroom \\
3 & Application of Tree & Inside Classroom \\
4 & Spanning Tree & Outside Classroom \\
5 & Post Test & Inside Classroom \\
\hline
\end{tabular}

Qualitative data were analyzed by conducting the students answer on post-test related to creativity indicators. The indicators were fluency, flexibility, and originality. The further description about indicators of creativity has been shown in Table 3.

Table 3. Description of Creativity Indicators

\begin{tabular}{cl}
\hline Aspects & \multicolumn{1}{c}{ Indicators } \\
Fluency & $\begin{array}{l}\text { Students could answer the problem more than twice } \\
\text { correctly }\end{array}$ \\
Flexibility & Students could perform a different solution \\
Originality & $\begin{array}{l}\text { Students could create new solution such that } \\
\text { different from others [22] }\end{array}$ \\
\hline
\end{tabular}




\subsection{Learning}

This section was focused on how the implementation of the flipped classroom using LMS Canvas. This analyzed were based on the students' activities during the course. All the activity was described clearly and included the conversation between lecturer and students.

\subsection{Students' Participation and Creativity}

This section was focused on students' participation and creativity during course. Through problem-solving tasks, students answer and give the reason for their argumentation. The students' participation was analyzed by asking a question, answering question, and argumentation. All their participation could be seen as their comments in a group discussion. The students' creativity was analyzed by students' answer sheet when they solved the openended problem. The open-ended problem was presented in the form of the online assignment and paper-based tasks.

The results of the questionnaire show that students do not experience difficulties when doing the registration of the lms and the activation of the courses. Students are asked to input NIM and PIC to login. The results of the questionnaire about the ease in the register shows $50 \%$ students find it very easy to login and activation courses. The lecturer provides a worksheet to be completed in groups. As much as $95 \%$ of the students agreed that the worksheet is not the form of matter of course but are the subject matter. As much as $45 \%$ of the students stated an understanding of the worksheet is easy enough to learn independently without the help of the lecturer. This is caused by the amount of English on the worksheet. As much as 55\% of the students argue that the discussion is able to motivate students to make jawbaan different from the guys his friend. In addition, as many as $40 \%$ of the students agreed that the discussion material make interested in providing comments to answer your other friends. The use of discussion method online is able to make $50 \%$ of the students were bold in commenting on the answers to other friends. The percentage of students who agree that the lecture online were able to motivate to ask the opinion of 50\%. As much as the other 50\% said that having lectures online is implemented, the lectures in class to motivate students expressed his opinion and ask the lecturer directly. The university as the organizer of online learning offers facilities such as internet network can be accessed by students for free. it is also highly approved by the students as much as $65 \%$.

\section{Result}

The research investigated how the students' participation and creativity toward the implementation of the flipped classroom. For the quantitative data, descriptive statistical analysis was performed the students' participant. Qualitative data was performed by students answer related to creativity aspects. The questionnaire result was used to collect and to describe demographic information from students. The questionnaire used Google Form and the URL was https://forms.gle/SvrfwMLUptnPNamb8. This demographic showed that 12 males and 8 females participated in the Discrete Mathematics course. They are engineering students in the first year. 


\subsection{Learning}

As the description about LMS Canvas, that is the open-source system, UMM used the domain of umm.ac.id. The Canvas could be accessed using lms.umm.ac.id. The course of Discrete Mathematics has been set by the university. After the domain has been changed, the UMM's logo appeared when the user in the login page.

The flipped classroom started by inside class through the content of the introduction of Tree. The course of Discrete Mathematics used modules that can be downloaded by students a day before. The module automatically is seen on Homepage in LMS Canvas after students sign in. The display of the homepage could be seen in Figure 1.

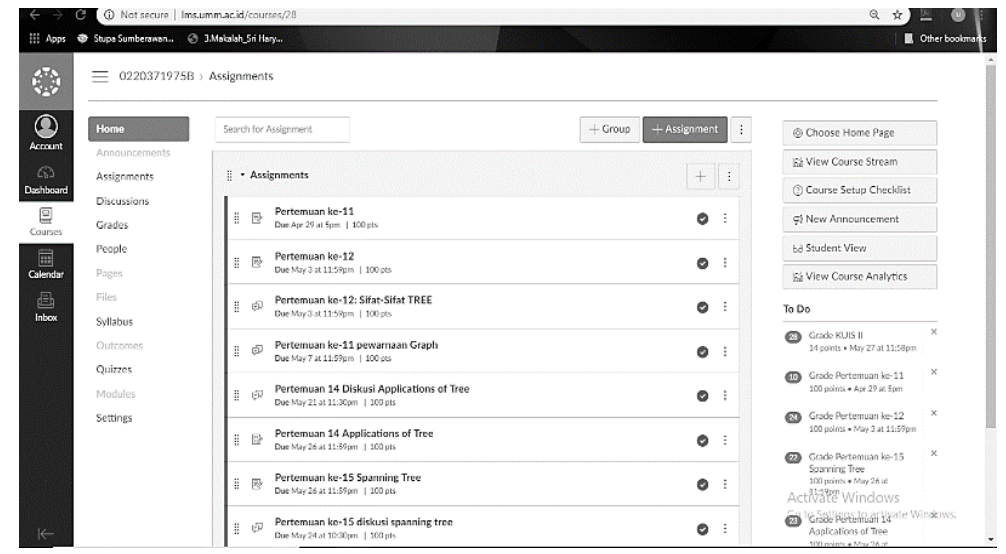

Fig. 1. LMS Canvas Layout.

Figure 1 showed the homepage of LMS Canvas. The position of the menu was in the left area in which contained Home, Announcement, Assignment, Discussion, Grade, People, Pages, Files, Syllabus, Outcomes, Quizzes, Modules, and Setting. After a post or upload module, the lecturer could check using students view in setting menu. There were two ways in submitting module that is, embed code using URS of Google Drive or the other drive application and share the link of the drive. When we embed code from the drive, the file in format doc usually being broken. Math equation could be read clearly. It could be different if the module was shared using URL drive.

The classroom activity started by presenting the problem in modules. The content that was presented in the first meetings was the introduction of the tree. The problem in the form of Exercise was discussed by the lecturer. The lecturer has been asked students how they get the answer, there is no student explain it. The problem is about identifying tree components, that is, parent, children, siblings, ancestors, descendants, internal vertices, leaves, and sub-tree. The picture of the tree was given by Figure 2.

Fig.2 is a tree. Students ask to identify all of the components. When he writes the answer on the board, he couldn't explain why Fig.2 doesn't have a descendant. The descendant of a vertex is all the vertices that become the branch vertex [23]. The question is how many vertices that was a descendant of $c$. The students said that the vertex $c$ doesn't have it. When the lecturer ask the reason, the students answered the vertex $c$ only have a child so there is no descendant. Lecturer asks more about the definition of descendant. All of the students only whisper each other. Then, the lecturer asks them to more loudly and there do still no one rising his/her hand. 
Finally, the lecturer calls a student using his name and he could explain the answer fluently. It could be explained that students actually could solve the problem but they did not explain bravely. This case was in-line with the previous study that explains engineering students have a critical performance in learning so that it would need the improvement of learning mathematics [8] [6].

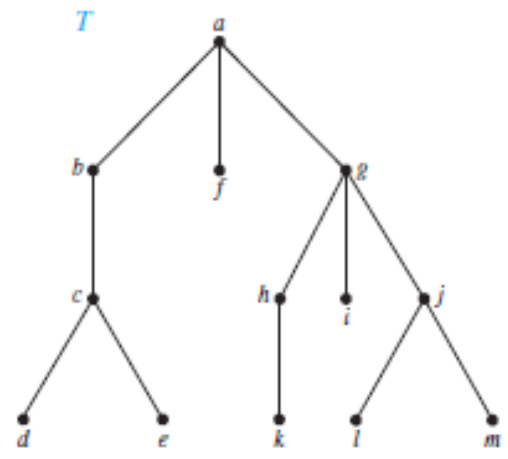

Fig 2. The Problem of Family Tree.

The second meeting was held by online learning using LMS Canvas. Learning topic was properties of the tree. In this course, students were given topic discussion. The topic discussion that presented in LMS Canvas was displayed on Figure 3.

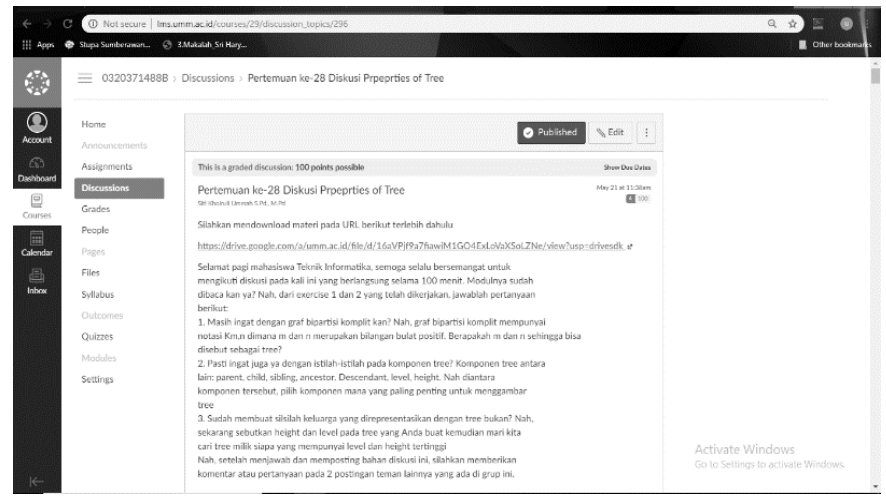

Fig. 3. The Topic Discussion.

Figure 3 showed the topic of discussion include the URL drive where the document file was saved. This topic related to previous content, that is, bipartite graph. Students have to investigate how the bipartite graph could be a tree. They have to write the reason clearly and remember what the component that bipartite have. One of the students answered the bipartite graph could transform into the tree if it has the component $m=1$ and $n>1$. The other student advice the bipartite graph could transform into the tree if one of $m, n=1$ then the other one must be more than one. The discussion is more active when the other student also commented including the figure of the graph. The discussion also becomes active when the students answer 
the third question. As the homework before, students were asked to draw a family tree and then they have to count the level and the height from their family tree. All of the students actively participated to answer these question because the end of the question was ask the student to mention who is the owner of the heaviest family tree. Based on Figure 3, on the up-right corner, it was shown that the total participation reached 100 comments. It means that students were more active to comment, give advice, and explain the reason in one session. This also being the study result that explains students more evident to answer the question in an online group discussion [21].

The third and fourth meetings discuss about the application of tree. Student asked to give the question compressing text using the binary tree. They have to create a binary tree that represented their favorite public figure. Engineering class was dominated by themale student so that almost a half students showed the name of favorite's football player. Every student attract to participate and challenged to guess the football player. It could be the findings of this research that the discussion could be more active when the discussion topic has more than one correct solutions. Students feel free to answer and the other student challenge to guess what the other students' questions. It was also related to the study that was conducted by Ya-Wen Lin. Her study result showed that students enjoy the math classroom during virtual online discussion [15] [24].

Every meeting in Discrete Mathematics Course followed by post-test. The post-test represent the content on module and topic discussion. The answer to post-test was varied because of the tasks related to their birth date, last name, or presence number. It could be reduced the students' cheat and motivate them to finish their post-test. This post-test that held on each meeting related to the research result which showed students assigned in every learning session [3].

\subsection{Students Participation and Creativity}

Students' Participation focused on how students involved the group discussion. The question from student appears in third meetings. One of the questions was about the existence of the spanning tree. The students also ask the other student about the subgraph formed by spanning tree. The other question is about how we could determine the spanning-tree formed from the special graph. All of the questions were so different topic and appears during the discussion when the other students answered. The number of comment could be seen at the Figure 4.

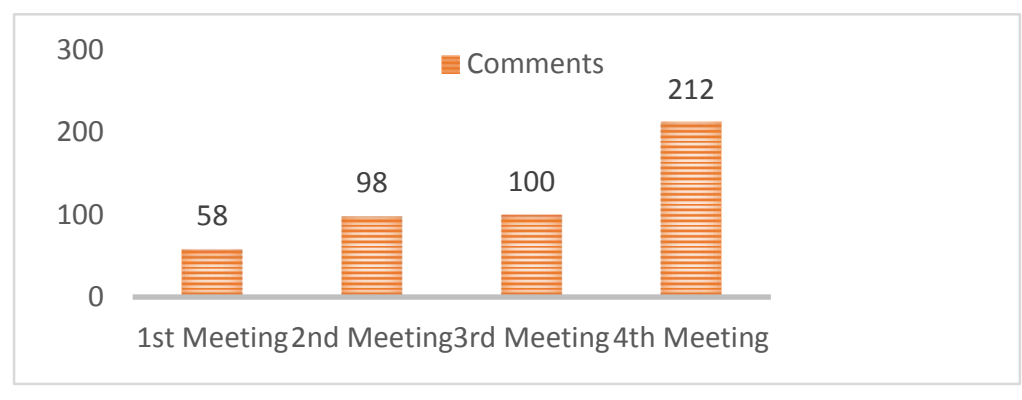

Fig 4. The Diagram of The Number of Students' comment. 
Fig.4 showed the number of comments in each meeting. The number of comment in the first meeting was 58 comments divided by answering the topic of discussion and feedback question. To illustrate the appearance of students' participation in group discussion, the following conversation between lecturer and student is provided below:

The lecturer presents a problem with the important of components composed tree. She wanted the students to identify how to compose a simple tree. The students' answer was so varied.

Student A: A graph could be expressed as a tree when the graph is not direct, connected and doesn't have a circuit.

Student B: You said that tree is not direct, is it means that it could be formed from a simple graph, multigraph, and pseudograph?

Student C: Based on your answer, is it possible to form a tree if it is only has one root and 10 vertices as children?

Student A: to Student B, it must be a simple graph and based on the definition of the child, there is no loop contained in the tree. Mam, is it possible to form a multiple edges? I give you an example. If tree being formed by two roots, as a parent, one vertex must be connected by two vertices as a root.

Based on the conversation, the student gives a question to the other student who has answered. Then, the other student answered back and ask a question to the lecturer to make sure that his answer is true. The student shares his idea to form a tree using two roots. The other students' responses showed the answer to a question. This conversation showed us how to vary of students' answer. The students could present the deep question of the problem and the continued problem about the tree that is formed by multiple edges. Although the students answer was incorrect, the students have been present their opinion bravely. It is related to the previous study that stated the students being more engaged with the open-ended tasks presented in Canvas [1]. The use of LMS contributed to the online discussion [25].

When the course is in the class, students are required to provide comments that support or reject the statement given by the lecturer.

Lecturer: Let $K_{n}, C_{n}$, and $W_{n}$. Try to sort those graph based on the sum of the activity of deleting edges so that the graph could form a tree

Student A: $C_{n}, K_{n}, W_{n}$

Student B: $W_{n}$ has the fewer edge to be deleted that $K_{n}$

Student $C$ : In my opinion, $K_{n}$ has the fewest deleted edge. Please try to compare $K_{3}$ and $W_{3}$

Student A: Let me try to sketch the graph first (he sketched the graph of $K_{3}$ and $W_{3}$ on the board) Well, we could see that $K_{3}$ only have one deleting edge then become a tree. In contrast, the graph of $W_{3}$ must be deleted 3 edges.

Student B: $O k$, how about the $K_{6}$ and $W_{6}$. I try to describe in advance (a student come to the board to sketch the graph K6 and W6). Well, in here, it could be seen that the K6 requires 25 times the deleting edge while the W6 requires 6 times the deleting edge.

Student $C$ : I agree if $K_{6}$ has the fewest deleting edges. Try the case of $K_{4}$ and $W_{4} . K 4$ requires 3 times the deleting edge while the $W_{4}$ requires 4 times the removal of the edge.

Student A: That is incorrect. The $W_{6}$ must have 20 times the deleting edges

Student B: But, in my opinion, $K_{6}$ have 30 edges, then if the spanning tree needs 5 edges, it must have 30-5 = 25 edges that become the deleting edges. 
Student A: (pointed out of the sketch) I disagree with you. If 1 vertice has 5 edges then other 5 vertices always have 4 edges that must be deleted. So, it must be $4 \times 5=20$ edges that must be deleted.

Student B: Correct. It must be 20 times to delete the edge.

Lecturer: Ok, I think we must draw the table to see the pattern

Student $C$ : (the students motivated to fill the table) So, the pattern changes if $n=5$. It could be concluded that for $n \geq 5$, the deleting edge of $K_{n}$ is more than $W_{n}$.

The interview shows the activity of the student to ask the opinion of the pros and cons of the amount of the removal edge for $K_{n}$ and $W_{n}$. Students pro is able to show by using the pictures on the board then practice the removal of the edge. A student whose cons do not use images to show the process of the removal of the edge. Besides, the students also do the pros and cons of the amount of edge in $K_{n}$ and $W_{n}$ which result in the difference in the amount of activity the removal of the edge. Pros and cons stop after the depiction of the graph by Student B who then deleted every edge of his graph one by one. The activity difference of opinion is also one of the forms of active participation of students in the class [18]. Earlier, the students are asked to read modules that have been uploaded on Canvas. When the discussion was held in Canvas, students do not feel difficulty in understanding modules. However, when given problems in class, the students of the different opinions which resulted in a several opinions expressed in class. The classroom atmosphere becomes very active when it occurs pros and cons. Students give suggestions to the student who was drawing on the board and shows the picture he made himself.

The creativity could be seen by the answer of the problem. The lecture gives a paper-based test. The test needs 60 minutes for student to complete all of the problems. One of the problems is finding the subtree of a rooted tree. Most student answer it correctly. As much as $85 \%$ of the students choose to create a subtree from the right side. it is then conducted interviews with 3 students who all draw the subtree of the right side. Students correctly said that the right side has a lot of children that allows have many types of the subtree. Figure $\mathbf{5}$ shows the answers of different students to draw a subtree.

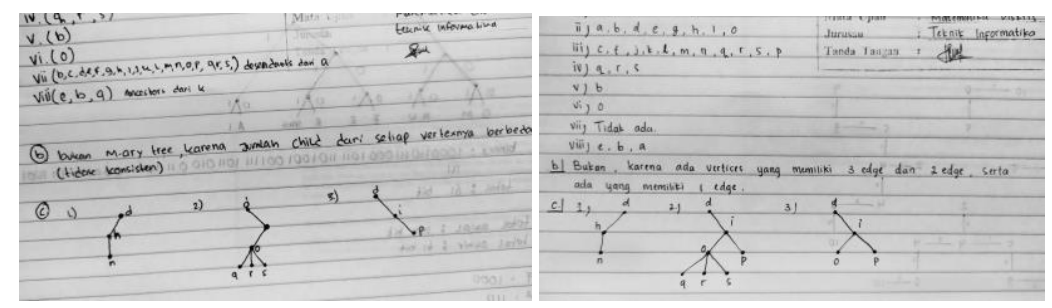

Fig. 5 Students` Answer.

Figure 5 could show us about the varety of students' answer. It could be said that the fluency has reached by students when they solved the problem. The students have their angle of view to create the subtree. the number of subtree that can be made is 20 subtrees. The number of students' answer is 18 subtrees. This means that the student has achieved an indicator of creativity, that is fluency when creating subtree. The number of the subtree that has created by students is correct. The number of answer is near to 20 subtrees. It is in line with the previous study that stated fluency could be seen by the number of vary answer [26].

The next indicator of creativity is flexibility. The flexibility could be seen from the students ${ }^{6}$ answer that is varies. The problem is about $m$-ary tree. Students are asked to investigate whether 
the tree is the $m$-ary tree. Students' answer was so varied. Student A stated that "The Tree is not an $m$-ary tree since parent $b$ has 3 children while the parent d has 2 children". Student B replied with "tree is not an m-ary tree because root a has 3 childrens but there is 1 child not being a parent". This means that there are different viewpoints between student A and student $\mathrm{B}$. this is in line with previous research stating that students referred to have creativity which is one of the aspects is the flexibility that is seen from the difference in problem-solving strategies used [22].

The originality could be seen by the students' answer that is different. It is depends on the problem that asked students to count the length of data using The Huffman Code. The students could answer using ASCII Table depend on their name. The students' answer could be seen on Figure 6 .

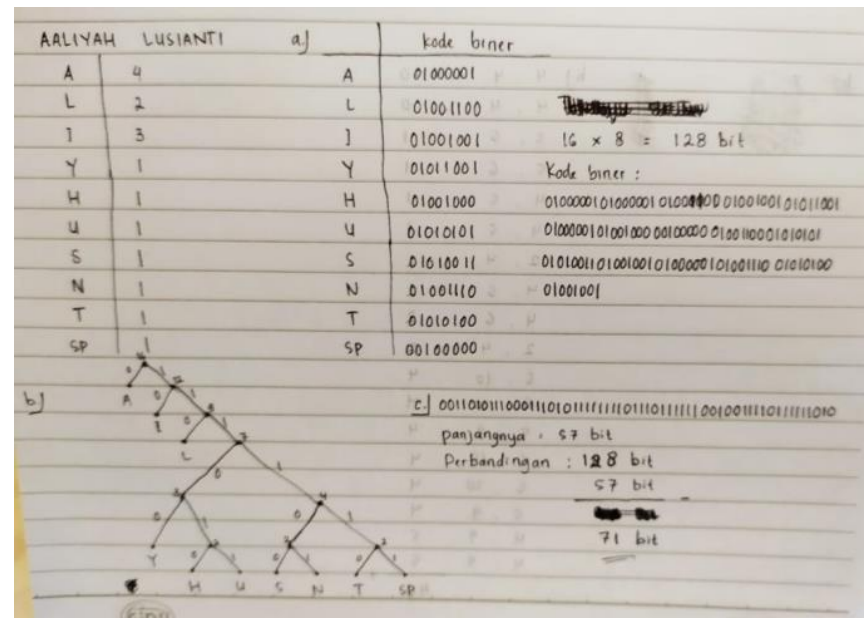

Fig. 6 Students‘ Answer about The Use of Huffman Coding.

The problem asked students to write their full name then sort the number of letters that appear with the sequence that starts from the letter the most. After that, students are asked to convert by using binary numbers according to the ASCII Table. Once converted, students are asked to describe a tree that represents a binary number such. Coding Huffman stressed to the order of occurrences of letters are the most widely first. Having known the letters, the branch of the tree selected from letters that have occurrences of the letters of the second largest and its position is determined by the alphabet. Originality can be directly seen because of the answers on students depends of each name so it may not be the same. The originality that appears in the test reaches $100 \%$. The originality appears to be based on the problem that's developed by the previous research. This is also one of the criteria about open-ended that can be used to measure creativity [2].

\section{Conclusion}

The novel of this study revealed the qualitative evidence to contribute the engineering students' participation and the creativity in the implementation of the flipped classroom method. It was found that students " participation is increasing in 4 meetings based on the number of students' comments and the variety of the comment. Students express their opinions bravely, 
commenting on friends' comments, and ask questions directly to the lecturer when the online discussion begins. The use of open-ended problems makes the students able to improve the ability of creativity through answers diverse. The implementation of the flipped classroom resulted in a very significant change for students that previously reserved. Students can display its performance in describing the graph on the board. The robust of this research is combining the flipped classroom with the use of open-ended problems in terms of student participation and creativity in solving the problems. It can also be used as an alternative method of online learning method that emphasizes honesty when completing the problems. Open-ended problems make the student not copy and paste answers from other friends or other online references.

The active participation of the student is visible from the increasing comments at every meeting clearly. Also, the appearance of the pros and cons to the answers students can bring up the comment being longer. Students are also able to actively participate in solving the problems during the learning in the class and then discuss with classmates.

The creativity that is based on the indicator of fluency, flexibility, and originality appears through learning upside down. Creativity is strongly influenced by the type of the given problem. A matter that demands a different answer from a different point of view can give rise to the overall indicator of creativity. Smoothness can be measured from the number of answers that emerged from each student according to the angle of view respectively. Flexibility is measured from the diversity of problem-solving strategies emerge. Originality was measured from the answers of each student are different from each other.

Acknowledgments. This research was conducted with the assistance of a Faculty of Teacher Training and Education block grant 2019. The authors would like to express their appreciation for the professional support provided by the staff of The University of Muhammadiyah Malang, specially in the Faculty of Teacher Training and Education.

\section{References}

[1] C. Moore and C.-J. Chung, "Students' Attitudes, Perceptions, and Engagement within a Flipped classroom model as Related to Learning Mathematics," J. Stud. Educ., vol. 5, no. 3, p. 286, (2015)

[2] G. S. Mason, T. R. Shuman, and K. E. Cook, "Comparing the effectiveness of an inverted classroom to a traditional classroom in an upper-division engineering course," IEEE Trans. Educ., vol. 56, no. 4, pp. 430-435, (2013)

[3] N. Ramakrishnan and J. J. Priya, "EFFECTIVENESS OF FLIPPED CLASSROOM IN MATHEMATICS," no. October, (2016)

[4] C. M. K. Zamzami Zainuddin, "Blended Learning Method Within Indonesian Higher Education Institutions," JPH - J. Pendidik. Hum., vol. 6, no. 1, pp. 69-77, (2018)

[5] Ş. Ş. DOĞRUER, "A Case Study on Mathematical Classroom Discourse in a Fifth Grade Classroom Beşinci Sınıf Matematiksel Söylem Üzerine Bir Durum Çalışması,” vol. 14, no. 1, pp. 299$322,(2015)$

[6] C. K. Lo, K. F. Hew, and G. Chen, "Toward a set of design principles for mathematics fl ipped classrooms: A synthesis of research in mathematics education,” Educ. Res. Rev., vol. 22, pp. 50-73, (2017)

[7] P. Yuanita, H. Zulnaidi, and E. Zakaria, "The effectiveness of Realistic Mathematics Education approach: The role of mathematical representation as mediator between mathematical belief and problem solving," PLoS One, vol. 13, no. 9, p. e0204847, Sep. (2018)

[8] Y. Lin, "The Effect of Blended Learning in Mathematics Course," vol. 8223, no. 415, pp. 741770, (2017) 
[9] J. Keengwe, "Blended Learning in Teacher Preparation Programs: A Literature Review A review of empirical research on blended learning in teacher education programs," no. April 2012, (2016)

[10] Y. W. Lin, C. L. Tseng, and P. J. Chiang, "The effect of blended learning in mathematics course," Eurasia J. Math. Sci. Technol. Educ., vol. 13, no. 3, pp. 741-770, (2017)

[11] J. B. Umoh and E. T. Akpan, "Challenges of Blended E-Learning Tools in Mathematics : Students 'Perspectives University of Uyo," vol. 3, no. 4, (2014)

[12] A. P. Lopes and F. Soares, "FLIPPING A MATHEMATICS COURSE , A BLENDED LEARNING APPROACH," no. March, pp. 3844-3853, (2018)

[13] W. Maciejewski, "Flipping the calculus classroom: An evaluative study," Teach. Math. its Appl., vol. 35 , no. 4, pp. 187-201, Dec. (2016)

[14] N. H. Wasserman, C. Quint, S. A. Norris, and T. Carr, "Exploring Flipped Classroom Instruction in Calculus III," Int. J. Sci. Math. Educ., vol. 15, no. 3, pp. 545-568, (2017)

[15] A. J. Carroll, MSLS, N. Tchangalova, MLS, AHIP, and E. G. Harrington, MLIS, "Flipping oneshot library instruction: using Canvas and Pecha Kucha for peer teaching," J. Med. Libr. Assoc., vol. 104, no. 2, pp. 125-130, (2017)

[16] R. G. Mimoza Petrova, Vanco Cabukovski, "SUPPORTING EDUCATION IN MATH SCIENCES WITH A LOW-BUDGET LMS SAKAI,” Математички Билтен, vol. 40, no. 2, pp. 95 108, (2016)

[17] B. Santikarn and S. Wichadee, "Flipping the classroom for English language learners: A study of learning performance and perceptions," Int. J. Emerg. Technol. Learn., vol. 13, no. 9, pp. 123-135, (2018)

[18] V. Moen and N. Helgevold, "The use of flipped classrooms to stimulate students' participation in an academic course in Initial Teacher Education,” Nord. J. Digit. Lit., vol. 9, no. 1, pp. 29-42, (2015) [19] M. F. Aqda, F. Hamidi, and M. Rahimi, "The comparative effect of computer-aided instruction and traditional teaching on student's creativity in math classes," Procedia Comput. Sci., vol. 3, pp. 266$270,(2011)$

[20] J. Sebastian and H. Huang, "Examining the relationship of a survey based measure of math creativity with math achievement: Cross-national evidence from PISA 2012," Int. J. Educ. Res., vol. 80, pp. 74-92, (2016)

[21] S. Sergis, D. G. Sampson, and L. Pelliccione, "Investigating the impact of Flipped Classroom on students' learning experiences: A Self-Determination Theory approach,” Comput. Human Behav., vol. 78, pp. 368-378, Jan. (2018)

[22] H. A. Syaibani, D. A, and H. A, "The Analysis of Student's Creative Thinking Skills in Solving 'Rainbow Connection' Problem through Research Based Learning,' Int. J. Soc. Sci. Humanit. Invent., vol. 4, no. 7, pp. 3783-3788, (2017)

[23] K. H. Rosen and K. H.

Discrete_Mathematics_and_Its_Applications_7Th_Edition_Rosen-1.Pdf.

[24] Y. W. Lin, C. L. Tseng, and P. J. Chiang, "The effect of blended learning in mathematics course," Eurasia J. Math. Sci. Technol. Educ., (2017)

[25] W. Imms and T. Byers, "Impact of classroom design on teacher pedagogy and student engagement and performance in mathematics," Learn. Environ. Res., vol. 20, no. 1, pp. 139-152, (2017)

[26] H. Kashefi, Z. Ismail, and Y. M. Yusof, “Supporting Engineering Students' Thinking and Creative Problem Solving through Blended Learning," Procedia - Soc. Behav. Sci., (2012) 